\title{
Middle-aged patient with haematochezia and anaemia presenting with rectal GIST
}

\author{
Dhilip Andrew 지 , Karthik Shyam 다, Jovis Johny, Rini Jose
}

Radiology, St John's Medical College Hospital, Bangalore, India

Correspondence to Dr Karthik Shyam;

dr.karthikshyam@gmail.com

Accepted 31 March 2021

\section{DESCRIPTION}

A 44-year-old female patient presented to the surgery outpatient department with 4 months history of bleeding per rectum and 1-month history of constipation. The patient also had history of loss of appetite and weight loss of $2 \mathrm{~kg}$ over last 1 month. The patient did not have any significant medical, surgical or family history. On examination, the patient had pallor and appeared emaciated. Her vital was stable, per abdomen was soft and unremarkable. On per rectal examination, a friable ulcerative proliferative growth was noted on anterior wall of rectum approximately $4 \mathrm{~cm}$ from anal verge. The rest of the systemic examinations were within normal limits. The patient had haemoglobin of $80 \mathrm{~g} / \mathrm{L}$, rest of the parameters were normal. On sigmoidoscopy a ulceroproliferative growth at $3 \mathrm{~cm}$ from anal verge was noted.

Non-contrast CT images revealed a heterogeneous mass with both endopytic and exophytic components. There is luminal stenosis of rectum due to endophytic component and inferiorly

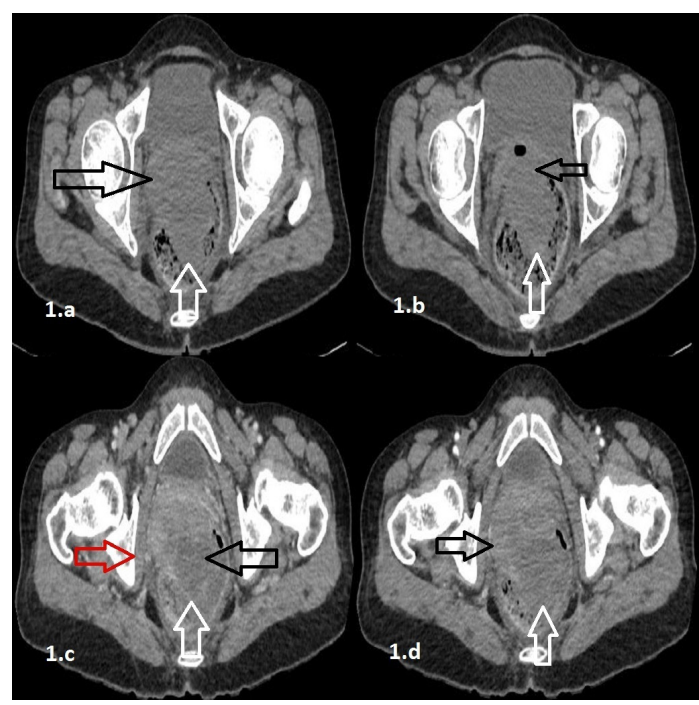

Figure $1 \quad(a, b)$ Plain axial CT scan images demonstrating iso to hypodense lesion arising from the anterior wall of rectum with exophytic (black arrow) and endophytic component (white arrow). (c) Postcontrast axial images demonstrating heterogeneously enhancing mass lesion with hypoenhancing areas (black arrow) within, endophytic component (white arrow) causing luminal narrowing and anterior extent of the lesion upto obturator internus muscle (red arrow). (d) Postcontrast axial images demonstrating heterogeneously enhancing mass lesion with exophytic (black arrow) and endophytic component (white arrow).

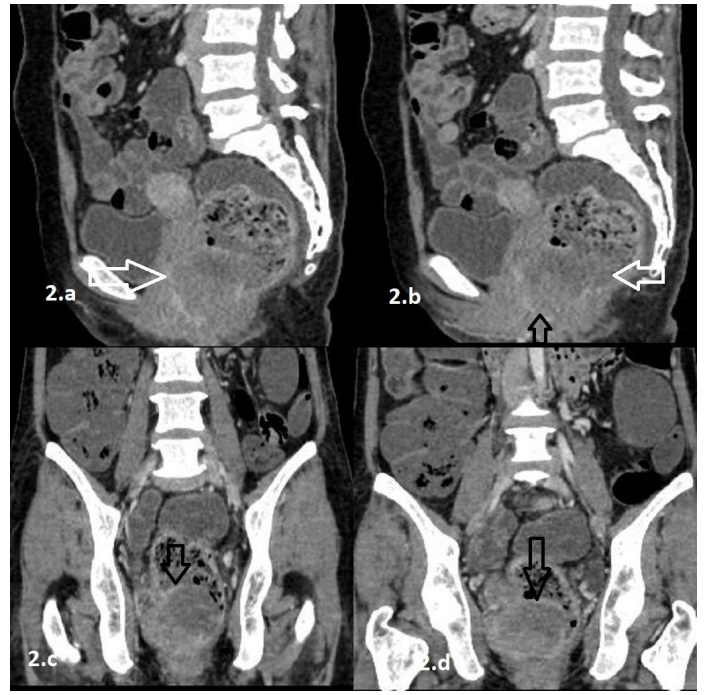

Figure 2 (a) Postcontrast sagittal images demonstrating involvement of cervix (white arrow). (b) Postcontrast sagittal images demonstrating enhancing bowel wall-based lesion with exophytic (black arrow) and endophytic component (white arrow). (c,d) Postcontrast coronal images demonstrating enhancing bowel wall based lesion (black arrow) $3 \mathrm{~cm}$ from anal verge.

the lesion extends into anal canal (figure 1A,B). On postcontrast images, solid parts of the lesion were enhancing while necrotic parts were hypo enhancing, Lesion extends anteriorly upto obturator internis muscle with maintained fat planes (figure 1C,D). The exophytic component had lost fat planes with cervix, (figure 2A-D). No features of any other similar lesion, lymphadenopathy or metastasis to other abdominal viscera were noted. On follow-up, the patient was advised for surgical resection but the patient refused surgery.

GIST is the most common mesenchymal tumour, usually occurs in stomach and small bowel. ${ }^{1}$ Rectal GISTs are uncommon, ${ }^{2}$ their presentation depends of tumour size. Small lesions can have a indolent course, larger lesions can present with rectal bleeding and constipation. ${ }^{3}$ They can present as predominantly exophytic lesion or exophytic lesion with endophytic component. ${ }^{4}$ CT scan can reliably detect, stage and assess treatment response of tumour. $^{56}$ On CT, they appear as a large heterogeneous enhancing mass with cystic degeneration, necrosis and haemorrhage. They can also present with ulceration and fistulisation of the gastrointestinal tract. ${ }^{78}$ Small Gastrointestinal Stromal Tumor (GIST) can be endoluminal and polypoidal with homogeneous appearance on $\mathrm{CT}^{6}{ }^{6}$ Close to $50 \%$ of 
cases present with metastasis, ${ }^{9}$ commonly to liver and peritoneum via haematogenous and peritoneal seeding, respectively. ${ }^{6}$

Postimatinib response is characterised by transition from heterogeneously hyperattenuating lesion to homogeneously hypoattenuating lesion due to myxoid degeneration; decrease in size and disappearance of enhancing nodule indicates response. ${ }^{6}$ Appearance of new enhancing tumour nodules within treated hypoattenuating lesion is suggestive of recurrence. An FDG-PET is considered whenever CT findings are inconsistent or inconclusive. MRI is an alternative if CT is contraindicated, they can detect small liver lesions. ${ }^{10}$

Complete surgical resection with tumour-free margin is the treatment of choice and the type of surgery is based on size and location of tumour. ${ }^{11}{ }^{12}$ Imatinib mesylate (IM) is the treatment of choice for metastatic and advanced cases of GIST. ${ }^{13}$ Since surgery can have up to $25 \%$ recurrence even in case of a low risk tumour, combination of surgery with perioperative IM treatment can improve surgical outcome and survival of the patient. ${ }^{14}$

\section{Learning points}

- GIST is common mesenchymal tumour, but rectal GISTs are uncommon.

- GIST can have endophytic and exophytic component, the symptoms depend on the size of the tumour.

- Contrast-enhanced CT is very good for evaluation of GIST.

Contributors All the four authors have contributed equally for the article. DA had drafted the article and chose the appropriate images, KS and JJ reviewed the article and made necessary changes. RJ had collected the necessary clinical details and provided inputs for drafting the article.

Funding The authors have not declared a specific grant for this research from any funding agency in the public, commercial or not-for-profit sectors.

Competing interests None declared.

Patient consent for publication Obtained.

Provenance and peer review Not commissioned; externally peer reviewed.

\section{ORCID iDs}

Dhilip Andrew http://orcid.org/0000-0002-6154-3063

Karthik Shyam http://orcid.org/0000-0003-0998-9604

\section{REFERENCES}

1 Miettinen M, Sarlomo-Rikala M, Lasota J. Gastrointestinal stromal tumors: recent advances in understanding of their biology. Hum Pathol 1999;30:1213-20.

2 Miettinen M, Sobin LH, Lasota J. Gastrointestinal stromal tumors of the stomach: a clinicopathologic, immunohistochemical, and molecular genetic study of 1765 cases with long-term follow-up. Am J Surg Pathol 2005;29:52-68.

3 Manouras A, Pappas A, Katergiannakis V, et al. Gastrointestinal stromal tumors of the rectum: report of five cases. Acta Gastroenterol Belg 2009;72:257-61.

4 Koch MR, Jagannathan JP, Shinagare AB, et al. Imaging features of primary anorectal gastrointestinal stromal tumors with clinical and pathologic correlation. Cancer Imaging 2012;12:557-65

5 Kalkmann J, Zeile M, Antoch G, et al. Consensus report on the radiological management of patients with gastrointestinal stromal tumours (GIST): recommendations of the German GIST imaging Working group. Cancer Imaging 2012;12:126-35.

6 Hong X, Choi H, Loyer EM, et al. Gastrointestinal stromal tumor: role of CT in diagnosis and in response evaluation and surveillance after treatment with imatinib. Radiographics 2006;26:481-95.

7 Burkill GJC, Badran M, Al-Muderis 0, et al. Malignant gastrointestinal stromal tumor: distribution, imaging features, and pattern of metastatic spread. Radiology 2003;226:527-32.

8 Levy AD, Remotti HE, Thompson WM, et al. Gastrointestinal stromal tumors: radiologic features with pathologic correlation. Radiographics 2003;23:283-304.

9 Nilsson B, Bümming P, Meis-Kindblom JM, et al. Gastrointestinal stromal tumors: the incidence, prevalence, clinical course, and prognostication in the preimatinib mesylate era-a population-based study in western Sweden. Cancer 2005:103:821-9.

10 Levy AD, Remotti HE, Thompson WM, et al. Anorectal gastrointestinal stromal tumors: CT and MR imaging features with clinical and pathologic correlation. Am J Roentgenol 2003;180:1607-12.

11 Cipolla C, Fulfaro F, Sandonato L, et al. Clinical presentation and treatment of gastrointestinal stromal tumors. Tumori J 2006;92:279-84.

12 Vasudeo V, Kumar U, Malua S. Rectal gastrointestinal stromal tumor: a case report. International Journal of Contemporary Medical Research 2016;3 https://www.ijcmr. com/uploads/7/7/4/6/77464738/_rectal_gastrointestinal_stromal_tumor_a_case_ report_.pdf

13 Demetri GD, von Mehren M, Blanke CD, et al. Efficacy and safety of imatinib mesylate in advanced gastrointestinal stromal tumors. N Engl J Med 2002:347:472-80.

14 Kameyama $\mathrm{H}$, Kanda T, Tajima Y, et al. Management of rectal gastrointestinal stromal tumor. Trans/ Gastroenterol Hepatol 2018;3:8.

Copyright 2021 BMJ Publishing Group. All rights reserved. For permission to reuse any of this content visit

https://www.bmj.com/company/products-services/rights-and-licensing/permissions/

BMJ Case Report Fellows may re-use this article for personal use and teaching without any further permission.

Become a Fellow of BMJ Case Reports today and you can:

- Submit as many cases as you like

- Enjoy fast sympathetic peer review and rapid publication of accepted articles

Access all the published articles

Re-use any of the published material for personal use and teaching without further permission

Customer Service

If you have any further queries about your subscription, please contact our customer services team on +44 (0) 2071111105 or via email at support@bmj.com.

Visit casereports.bmi.com for more articles like this and to become a Fellow 